\title{
Rumpon Atraktor ljuk: Teknologi Alat Bantu Penangkapan Ikan untuk Nelayan Kabupaten Nagan Raya, Provinsi Aceh
}

\section{Palm Fiber FADs: Fishing Aids Technology for Fishermen in Nagan Raya District, Aceh Province}

\author{
Hafinuddin $^{1 *}$, Edwarsyah $^{2}$, Muhammad Rizal $^{1}$ \\ ${ }^{1}$ Program Studi Perikanan, Fakultas Perikanan dan Ilmu Kelautan, Universitas Teuku Umar \\ ${ }^{2}$ Program Studi Sumber Daya Akuatik, Fakultas Perikanan dan Ilmu Kelautan, Universitas Teuku Umar \\ *Korepondensi: hafinuddin@utu.ac.id
}

\begin{abstract}
ABSTRAK
Penggunaan rumpon tradisional sebagai alat bantu penangkapan ikan jaring insang permukaan untuk penangkapan ikan pelagis yang dilakukan oleh mitra kelompok nelayan di Kecamatan Kuala Pesisir Kabupaten Nagan Raya, menyebabkan biaya operasional/maintenance yang tinggi sehingga keuntungan nelayan jaring insang cenderung kecil. Selain itu, daun pinang atau daun kelapa semakin sulit untuk diperoleh. Oleh karena itu, teknologi rumpon ijuk diharapkan mampu meningkatkan pendapatan nelayan jaring insang permukaan. Pendekatan dalam penyelesaian permasalahan yang telah dilakukan adalah dengan edukasi, pelatihan dan pedampingan. Kegiatan program kemitraan masyarakat (PKM) ini telah dilakukan mulai bulan Maret-November 2018. Luaran kegiatan PKM adalah peningkatan pengetahuan dan ketrampilan bagi masyarakat nelayan. Selain itu, diharapkan kualitas teknologi yang diterapkan (rumpon ijuk) dapat lebih baik dari rumpon tradisional dan produksi hasil tangkapan nelayan jaring insang permukaam dapat meningkat.
\end{abstract}

Kata Kunci: rumpon ijuk, Arenga pinnata, program kemitraan masyarakat, gill net, Kabupaten Nagan Raya

\begin{abstract}
Traditional fish aggregating devices (FADs) as fishing aids for surface gill net to catch pelagic fish were used by fishery community partner at Kuala Pesisir Sub District Nagan Raya District, so that operational/maintenance is high cost and those incomes of gill net's fishermen obtains small. Therefore, palm fiber FADs technology is expected to alternatively increase income of surface gill net fishermen. Education, training, and accompaniment is approached to accomplish fishermen problems. Community partnership programe (PKM) was conducted in March until November 2018. Community partnership programe has increased knowledge and skill for fishery community. In addition, the quality of palm fiber FADs technology is better than the traditional FADs and production of fish catching.
\end{abstract}

Key word: Palm fiber FADs, Arenga pinnata, Community Partnership Programe, Gill net, Nagan Raya District

\section{PENDAHULUAN Latar Belakang}

Kabupaten Nagan Raya merupakan salah satu Kabupaten yang berbatasan dengan Samudera Hindia dan terletak di pantai barat Sumatera. Kabupaten ini memiliki produksi hasil tangkapan ikan di perairan laut mencapai 4.567,7 ton atau mencapai Rp 116.964.154.000,-Alat penangkapan ikan yang dominan di kabupaten ini adalah jaring insang (gill net) yang mencapai $76.65 \%$ (289 unit) dari total alat tangkap 377 unit dan dalam kategori jaring insang, jaring insang permukaan merupakan alat tangkap yang paling banyak digunakan oleh nelayan Kabupaten Nagan Raya yang berjumlah 237 unit (DKP Provinsi Aceh, 2014). 
Nelayan jaring insang permukaan menggunakan armada penangkapan ikan dengan dengan jenis motor tempel dan menggunakan alat bantu penangkapan ikan yaitu rumpon tetap permukaan.

Menurut Taquet (2011) dalam Konferensi Internasional di Tahiti "Tuna fisheries and FADs", menjelaskan bahwa penggunaan teknologi rumpon dapat memaksimalkan hasil tangkapan. Selain itu, Taquet (2011) juga menjelaskan bahwa program rumpon (Fish aggregating device/FAD) memiliki manfaat seperti 1) meningkatkan efiseinsi penangkapan; 2) meningkatkan catch per unit effort (CPUE); 3) meminimumkan biaya penangkapan (terutama bahan bakar minyak).

Komponen rumpon terdiri dari pelampung (float), tali (rope), pengumpul ikan (attractor) dan pemberat (anchor). Altinagac et al. (2010) menjelaskan bahwa atraktor merupakan salah satu komponen utama pada rumpon karena berfungsi sebagai alat pengumpul ikan sesungguhnya.

Hasil penelitian Baihaqi (2014) menunjukkan produktivitas hasil tangkapan atraktor ijuk yang cenderung sama dengan daun kelapa, namun daya tahan atraktor ijuk lebih baik dari daun kelapa dengan masa perendaman yang sama di laut (Baihaqi, 2014). Hasil penelitian Yusfiandayani (2004) menjelaskan bahwa daya tahan dari atraktor daun kelapa adalah 3-4 minggu, sedangkan daya tahan rumpon adalah 3-4 bulan. Sedangkan menurut Ibrahim et al. (2014) atraktor daun kelapa hanya mampu bertahan 3 bulan perendaman di laut.

Nelayan jaring insang permukaan di Kabupaten Nagan Raya menggunakan rumpon tetap (anchor fish aggregating devices/AFADs) dengan menggunakan atraktor daun kelapa atau daun pinang. Modifikasi material untuk alat bantu penangkapan ikan rumpon sangat penting dilakukan. Hal ini agar daya tahan atraktor mampu ditingkatkan sehingga biaya perawatan (maintenance) dari rumpon akan berkurang dan akan menguntungkan bagi nelayan jaring insang permukaan.

Hafinuddin dan Mahendra (2016) menyebutkan bahwa rumpon atraktor ijuk memberikan nilai ekonomis yang lebih tinggi dibandingkan dengan rumpon dengan atraktor yang menggunakan daun kelapa atau daun pinang. Hal ini dikarenakan biaya perawatan rumpon atraktor ijuk lebih kecil dari rumpon atraktor daun pinang atau daun kelapa.

Selain itu, Ibrahim et al. (1996) menjelaskan bahwa lama perendaman atraktor akan berpengaruh terhadap jumlah ikan yang akan berkumpul di sekitar rumpon. Hal ini disebabkan karena periode perendaman akan menstimulus hadirnya organisme akuatik sehingga ketersediaan makanan di sekitar rumpon cenderung akan semakin meningkat.

Kondisi mitra yang masih menggunakan atraktor daun kelapa atau daun pinang telah memberikan biaya operasional (maintenance) yang tinggi yaitu dengan biaya per 3 bulan adalah Rp 1.000.000 - 1.500.000. Kondisi mitra yang sangat membutuhkan teknologi material baru untuk bahan atraktor rumpon sehingga pengadobsian teknologi tepat guna dan ramah lingkungan adalah kebutuhan yang tidak bisa ditunda lagi.

Mitra kelompok nelayan yang dipilih adalah kelompok nelayan yang berada di Desa Kuala Trang Kecamatan Kuala Pesisir Kabupaten Nagan Raya, yang selama ini melakukan penangkapan ikan pelagis dengan menggunakan alat tangkap jaring insang permukaan dan alat bantu penangkapan rumpon atraktor daun alami yaitu daun pinang/daun kelapa.

\section{Masalah}

Beberapa permasalahan mitra/nelayan jaring insang permukaan dengan alat bantu rumpon atraktor daun pinang atau daun kelapa antara lain: (1) alat bantu penangkapan ikan rumpon atraktor daun pinang atau daun kelapa mengakibatkan biaya operasional tinggi, (2) 
kurangnya informasi bahan pengganti rumpon atraktor daun pinang atau daun kelapa untuk penangkapan ikan pelagis ekonomis penting dengan alat tangkap jaring insang permukaan, (3) masih sangat bergantungnya mitra/nelayan pada atraktor daun pinang atau daun kelapa sehingga biaya investasi yang dikeluarkan cenderung besar, (4) armada penangkapan ikan motor tempel dengan ukuran kapal $<12$ m sehingga nelayan lebih banyak tidak dapat melaut terutama ketika musim peralihan timur-barat.

\section{METODE}

Penerapan rumpon atraktor ijuk sebagai alternatif teknologi alat bantu penangkapan jaring insang permukaan telah dilakukan dengan pendekatan edukasi, pelatihan dan pendampingan (Hafinuddin dan Hasanah, 2017; Hafinuddin dan Edwarsyah, 2017). Adapun tahapan yang dilakukan dalam kegiatan pengabdian kepada masyarakat nelayan jaring insang permukaan adalah sebagai berikut:

1) Edukasi dan pendampingan mengenai rumpon atraktor ijuk dan alternatif alat tangkap lainnya kepada anggota kelompok nelayan mitra. Kegiatan dilakukan dalam bentuk diskusi interaktif langsung kepada anggota kelompok nelayan mitra dengan tujuan membuka wawasan mengenai rumpon atraktor ijuk dan alat tangkap lain yang dapat digunakan di sekitar rumpon;

2) Pelatihan pembuatan rumpon atraktor ijuk meliputi:

(1)Penyiapan alat dan bahan pembuatan rumpon atraktor ijuk dan alat tangkap alternatif seperti pancing ulur dan bubu dasar;

(2)Penentuan daerah pemasangan rumpon atraktor ijuk yang tepat

(3) Pembuatan rumpon atraktor ijuk dan alat tangkap alternatif seperti pancing ulur dan

(4)Pengoperasian alat tangkap jaring insang dan pancing ulur di sekitar rumpon atraktor ijuk.

Kegiatan program kemitraan masyarakat ini melibatkan langsung anggota kelompok mitra mulai dari penyiapan alat dan bahan yang digunakan, teknik pembuatan alat tangkap, proses penentuan daerah tangkapan (fishing ground) dan teknik pemasangangan rumpon ijuk di perairan. pengoperasian alat tangkap. Pendampingan kegiatan tetap dilakukan untuk memastikan kegiatan dapat berjalan sebagaimana yang diharapkan.

\section{HASIL DAN PEMBAHASAN}

Kegiatan pengabdian kepada masyarakat yaitu rumpon atraktor ijuk untuk nelayan jaring insang permukaan terdiri atas:

1) Penentuan lokasi pemasangan rumpon

Rumpon yang dipasang berjumlah 6 unit yaitu 3 unit rumpon atraktor ijuk dan 3 unit atraktor daun kelapa. Lokasi pemasangan rumpon atraktor ijuk dan atraktor daun kelapa berada pada kedalaman 15-25 meter atau berjarak 3 mil dari PPI Kuala Tadu, Kabupaten Nagan Raya. Substrat dasar laut adalah lumpur berpasir.

2) Pembuatan kerangka atraktor ijuk 
Atraktor ijuk terbuat dari besi hallow galvanis adalah dengan panjang 3 meter, lebar 3 meter dan tinggi 3 meter. Luas atraktor ijuk yang berbentuk prima tegak segi empat adalah $27 \mathrm{~m}^{3}$ (Gambar 1).

Kerangka atraktor kemudian dilapisi dengan ijuk sehingga bagian/sisi-sisi dari besi akan tertutupi dengan ijuk. Selain itu, antara satu sisi rangka dengan lainnya dipasang tali dari serat ijuk. Gambar 2 menunjukkan kerangka atraktor telah menjadi atraktor ijuk.

3) Pemasangan (setting) rumpon ijuk di perairan laut dangkal

Rumpon ijuk sebanyak 3 unit telah dipasang di Perairan Kuala Tadu. Lokasi setting rumpon ijuk berada pada jarak 3 mil dari PPI Kuala Tadu dengan lama tempuh dari fishing base adalah 1 jam dan kedalaman perairan di lokasi pemasangan rumpon adalah 20-30 meter. Selain pemasangan rumpon ijuk, juga dilakukan pemasangan rumpon daun kelapa sebanyak 3 unit, dimana 1 unit rumpon daun kelapa menggunakan 50 pelepah kelapa.

4) Penangkapan ikan di sekitar rumpon

Penangkapan ikan di sekitar rumpon ijuk dan rumpon daun kelapa menggunakan pancing ulur dan jaring insang dasar serta jaring insang permukaan. Penangkapan dengan pancing ulur atau pancing ramet menggunakan mata pancing yang memiliki bulu-bulu plastik. Bulu-bulu plastik digunakan sebagai pemikat ikan pelagis. Ikan yang tertangkap dengan pancing ulur adalah ikan ekor kuning, ikan kembung, ikan mata besar, ikan lemuru.

Ikan yang tertangkap dengan menggunakan jaring insang permukaan adalah ikan lemuru. Sedangkan ikan yang tertangkap dengan jarring insang dasar adalah ikan kembung, ikan gabus laut, ikan ekor kuning, ikan sebelah, ikan betok dan rajungan.

\section{PENUTUP}

Pengabdian PKM pemanfaatan rumpon atraktor ijuk (Arenga pinnata) bagi nelayan jaring insang permukaan di Kecamatan Kuala Pesisir Kabupaten Nagan Raya telah dilaksanakan dalam sejumlah kegiatan meliputi edukasi tentang rumpon atraktor ijuk, survei awal lokasi pemasangan rumpon atraktor ijuk, peletakan rumpon daun kelapa sebagai rumpon kontrol untuk pemasangan rumpon ijuk, pelatihan pembuatan atraktor ijuk dan pemasangan rumpon atraktor ijuk serta uji penangkapan ikan di sekitar rumpon ijuk. Kegiatan PKM ini diharapak dapat berkelanjutan menjadi sebuah usaha yang menguntungkan (profitable) bagi nelayan jaring insang.

\section{UCAPAN TERIMA KASIH}

Ucapan terima kasih disampaikan kepada:

1) Kementerian Riset, Teknologi dan Pendidikan Tinggi yang telah memberikan pendanaan melalui hibah pengabdian kepada masyarakat skim Program Kemitraan Masyarakat (PKM).

2) Nelayan perintis jaring insang permukaan di Gampong Kuala Trang Kecamatan Kuala Pesisir Kabupaten Nagan Raya sebagai pihak mitra. 
3) Aparatur Gampong Kuala Trang Kecamatan Kuala Pesisir Kabupaten Nagan Raya yang telah memberikan ijin dan memfasilitasi kegiatan ini.

4) Bapak Muhammad Agam Tahir, S.Pi., M.Si (Dosen Prodi Perikanan Fakultas Perikanan dan IImu Kelautan Universitas Teuku Umar) dan Sdr. Sayid Geubri Alfarisi, S.IK (tenaga lapang kegiatan PKM) serta Abdul Karim, Mardhiah, Isma Safria (mahasiswa Prodi Perikanan Fakultas Perikanan dan IImu Kelautan Universitas Teuku Umar) yang telah banyak membantu kegiatan ini.

\section{DAFTAR PUSTAKA}

Baihaqi, L. I. 2014. Perbandingan karakteristik ikan pada rumpon dengan atraktor ijuk dan atraktor daun kelapa di Perairan Pulau Tunda Banten. Skripsi [Tidak dipublikasikan]. Departemen Pemanfaatan Sumberdaya Perikanan Fakultas Perikanan dan IImu Kelautan Institut Pertanian Bogor. Bogor.

DKP Provinsi Aceh. 2014. Statistik Perikanan Tangkap. Sumber: dkp.acehprov.go.id diakses 5 Mei 2017.

Hafinuddin \& Edwarsyah. 2017. Teknologi penangkapan rajungan (Portunus pelagicus spp.) ramah lingkungan dengan bubu kubah di Kabupaten Aceh Barat Provinsi Aceh. Marine Kreatif, 1 (1): 1-7.

Hafinuddin \& Hasanah, U. 2017. Penerapan perangkap lipat (traps) untuk penangkapan kepiting bakau (Scylla sp.) di Kabupaten Aceh Barat Provinsi Aceh. Marine Kreatif, 1(1): 30-36.

Hafinuddin \& Mahendra. 2016. Pemanfaatan ijuk (Arenga pinnata) sebagai alternatif natural atraktor pada rumpon laut dangkal Perairan Meulaboh Kabupaten Aceh Barat. Laporan Tahun Terakhir Penelitian Dosen Pemula. Universitas Teuku Umar. Meulaboh.

Ibrahim, S., Ambak, M. A., Shamsudin, L. \& Samsudin, M. 1996. Importance of fish aggregating devices (FADs) as subtrates for food organisms of fish. Fisheries Research, 27(4), 265-273.

Ibrahim, S., Hasaruddin, H., Hussin W. M. R. W. \& Ahmad W. M. A. W. 2014. Durability of coconut fronds as attractors for fish aggregating devices (FADs): an observation based on leaf epidermis structure. AACL Bioflux, 7(3), 225-233.

Taquet, M. (2011, September). Artisanal and industrial FADs: A question of scale. SPC Fisheries Newsletter, 136(December), 35-45. Retrieved from http://www.spc.int/coastfish/en/publications/bulletins/fisheries-newsletter/399spc-fisheries-newsletter-136.html

Yusfiandayani, R. 2004. Study on the aggregation mechanism of small pelagic fish around rumpon and its fisheries of development in Pasauran Waters, Province of Banten. Unpublished doctoral's thesis, Bogor Agricultural University, Bogor, Indonesia. 


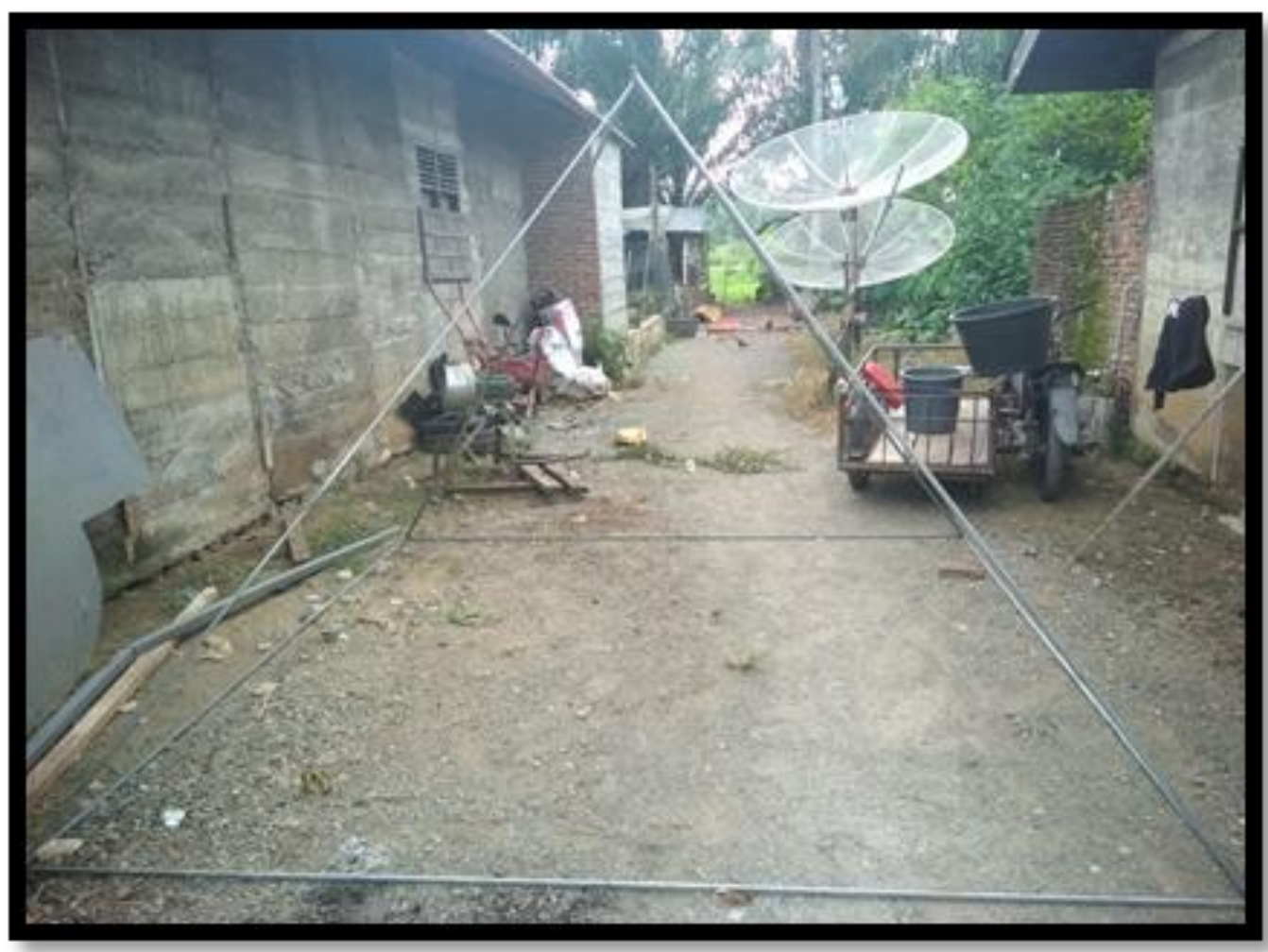

Gambar 1 Kerangka atraktor ijuk

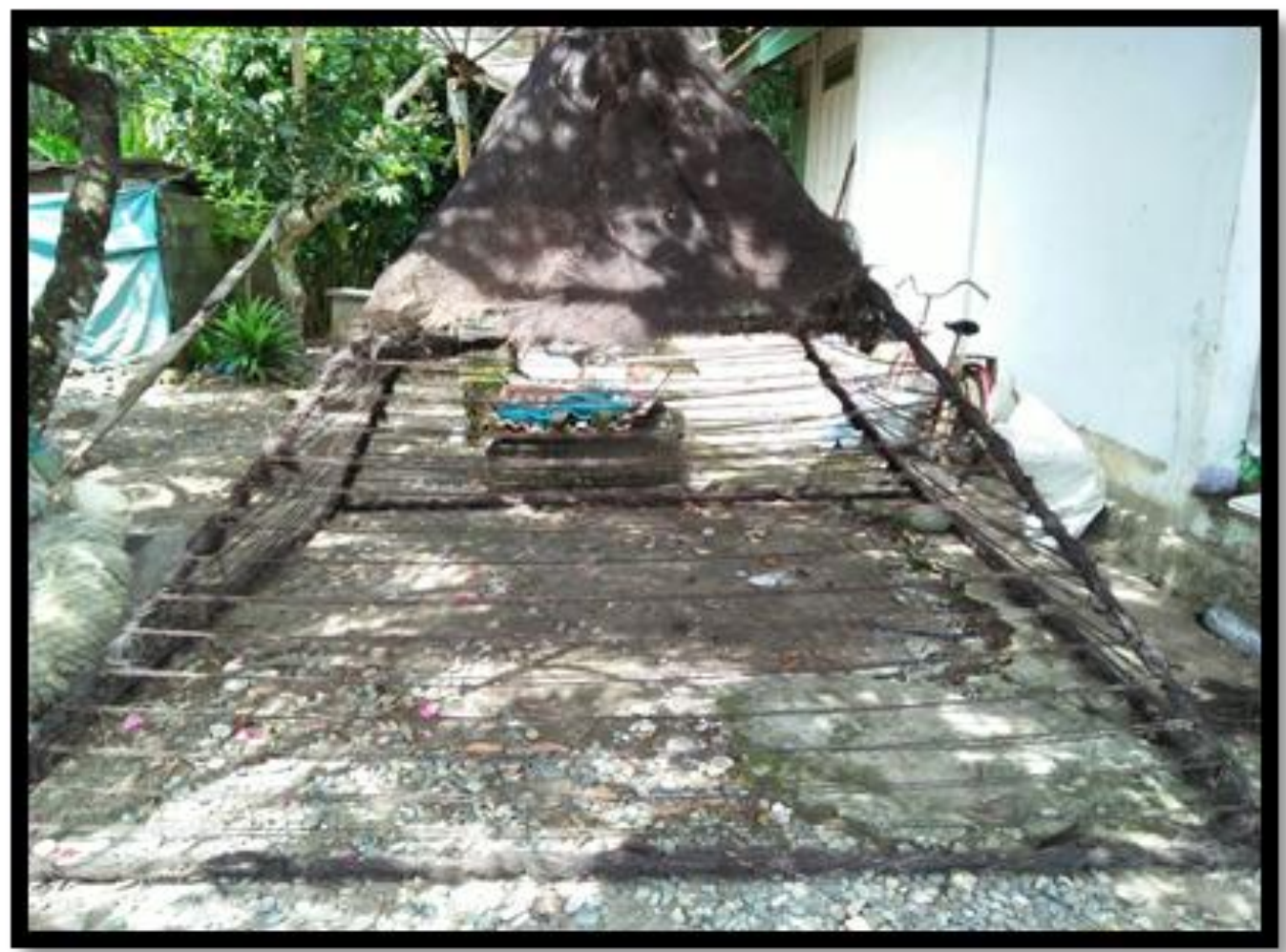

Gambar 2 Atraktor ijuk 